\title{
Karakteristik Komposit Semen Limbah Partikel Bambu Dan Serat Aren Untuk Bahan Bangunan
}

\author{
${ }^{\square}$ Nor Intang Setyo Hermanto', Yanuar Haryanto², IGL Bagus Eratodi ${ }^{3}$ \\ 1,2 Jurusan Teknik Sipil, Fakultas Teknik Universitas Jenderal Soedirman (Unsoed) \\ ${ }^{3}$ Jurusan Teknik Sipil, Fakultas Teknik dan Informatika, Universitas Pendidikan Nasional (Undiknas)
}

\section{Kata Kunci/ Keywords :}

palm, bamboo, composite, characteristic, cement

aren, bambu, komposit, karakteristik, semen.

\begin{abstract}
Abstrak:
This paper discusses the physical and mechanical characteristics of cement composed with bamboo particle and sugar palm fiber wastes in various mixture compositions to obtain the empirical formulation in predicting the mechanical characteristics. The results show that the best physical charateristic behavior is obtained in the composition of cement and material with the comparison of 1:4 and bamboo particle sizes of 0.2 $\mathrm{cm} \times 0.2 \mathrm{~cm}$ and $0.5 \mathrm{~cm} \times 0.5 \mathrm{~cm}$. The study on mechanical charactristics shows that cement beam's/board's Modulus of Rupture (MOR) is about 4.77-6.59 MPa, while the greatest result of cement beam composition is that composed with bamboo particles and sugar palm fibers by $50 \%: 50 \%$ with bamboo particle size of $0.2 \mathrm{~cm} \times 0.2 \mathrm{~cm}$ and sugar palm fiber length of $5 \mathrm{~cm}$. Meanwhile, the highest cement beam's Modulus of Elasticity (MOE) is obtained at that composed with the mixture of bamboo particles and sugar palm fibers of $100 \%: 0 \%$ and bamboo particle size of $0.2 \mathrm{~cm} \times 0.2 \mathrm{~cm}$. The best cement content for MOE is 2283.02 MPa obtained at the composed cement and material with the comparison of 1:3.
\end{abstract}

\begin{abstract}
Makalah ini membahas karakteristik fisik dan mekanik komposoit semen limbah partikel bambu dan serat aren dengan variasi komposisi campuran untuk memperoleh formulasi empiris guna memprediksi sifat mekaniknya. Hasil kajian memperlihatkan bahwa perilaku sifat fisik terbaik diperoleh pada perbandingan bahan dan semen 1:4 dan ukuran partikel bambu $0,2 \mathrm{~cm} \times 0,2 \mathrm{~cm}$ dan 0,5 $\mathrm{cm} \times$ $0,5 \mathrm{~cm}$. Kajian sifat mekanik menunjukkan tegangan lentur (MOR) balok/papan semen berkisar 4,77-6,59 MPa, dengan hasil terbesar pada komposisi balok semen campuran partikel bambu dan serat 50\%:50\% dengan ukuran partikel bambu 0,2 cm x 0,2 cm dan panjang serat aren $5 \mathrm{~cm}$. Modulus elastisitas (MOE) balok semen tertinggi diperoleh pada campuraan partikel bambu dan serat aren 100\%:0\% dan ukuran partikel bambu 0,2 cm x 0,2 cm. Kandungan semen terbaik untuk MOE sebesar 2283,02 MPa didapat pada perbandingan bahan dan semen 1:3.
\end{abstract}

Sitasi:

Hermanto, Nor Intang Setyo, dkk. (2017). Karakteristik Komposit Semen Limbah Partikel Bambu dan Serat Aren Untuk Bahan Bangunan. Jurnal Teknik Sipil \& Perencanaan, 17(2), $77-82$.

(C) 2017 Universitas Negeri Semarang

\footnotetext{
Nor Intang Setyo Hermanto : Jurusan Teknik Sipil, Fakultas Teknik Universitas Jenderal Soedirman, Purwokerto E-mail : intang_sh@yahoo.com
} 


\section{PENDAHULUAN}

Seiring semakin sulitnya kayu diperoleh dan harganya juga semakin mahal akibat luas kawasan hutan Indonesia cenderung semakin berkurang, maka berbagai upaya telah dilakukan, diantaranya efisiensi pemanfaatan bahan baku, peningkatan rendemen, peningkatan diversifikasi produk, peningkatan masa pakai kayu, pemanfaatan lesser known species, pemanfaatan limbah (kayu) baik limbah yang berasal dari pemanenan hasil hutan/pertanian maupun dari industri pengolahan kayu, pemanfaatan jenis-jenis kayu bermutu rendah maupun kayu berdiameter kecil (Syafi'i, 1999). Upaya menciptakan produk papan semen komposit olahan telah banyak dilakukan dengan memanfaatkan limbah seperti serbuk gergaji, kertas, kardus, sampah daun, potongan kain, sabut kelapa, serat ijuk, dan sebagainya.

Limbah yang lain adalah dari hasil industri pengolahan tepung aren. Limbah dari hasil industri pengolahan tepung aren adalah berupa limbah padat dan cair. Khusus limbah padat adalah berupa kulit kayu dan ampas berbentuk serat/serabut sisa perasan tepung aren (Hermanto dkk, 2005; Handajani dan Firdayanti, 2005). Limbah kayu pohon aren sebagian besar pemanfaatnya sebagai kayu bakar, tangkai cangkul, tangkai kapak dan barang kerajinan. Sedangkan limbah ampas serat aren menyerupai serabut kelapa hampir tidak dimanfaatkan sama sekali dan dibuang begitu saja disekitar pabrik pengolahan industri tepung aren yang umumnya terletak di bantaran tepi sungai sehingga mencemari lingkungan (Hermanto dkk, 2005; Handajani dan Firdayanti, 2005).

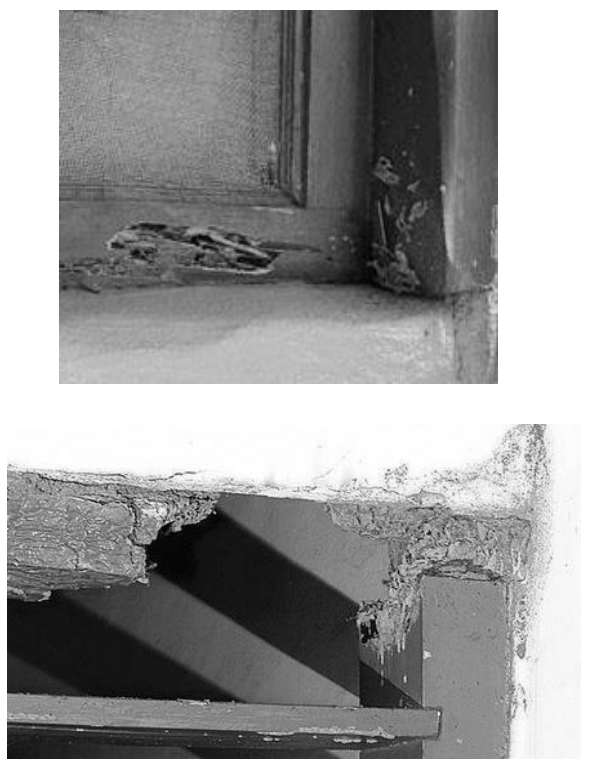

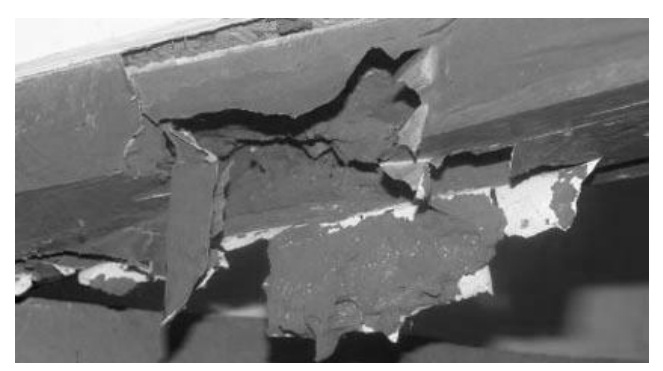

Gambar 1. Kusen kayu yang keropos dan lapuk

Komponen bahan bangunan seperti eternit panel dinding, dan kusen pada umumnya terbuat dari bahan komposit semen dan kayu. Kusen dari bahan kayu belum tergantikan secara signifikan dari segi keindahan, penyerapan energi, dan kemudahan pengerjaan dibandingkan upaya penggantinya seperti kusen aluminium dan beton. Penggantian kusen kayu dengan alumunium dan beton dikarenakan bahan kayu sudah mulai mahal. Kelemahan bahan kayu pada kusen yang lain adalah terjadinya keropos pada kusen kayu akibat pelapukan (rayap, kumbang bubuk, dan sebagainya) seperti terlihat pada Gambar 1.

Akibat kelemahan bahan kusen dari kayu, banyak berkembang saat ini kusen dengan bahan alumunium dan beton. Namun bahan kusen alumunium juga mempunyai kelemahan seperti harga mahal dan pengerjaan sulit. Bahan kusen beton memiliki kelebihan dari segi murah dan awet, namun bahan relatif berat dan sulit untuk pemasangan aksesoris (engsel dan sebagainya). Solusi yang dapat dikedepankan untuk mengatasi segala kelemahan dan mempertahankan/meningkatan keunggulan adalah dengan menciptakan kusen dari bahan papan/balok semen komposit partikel/serat kayu/bambu. Balok semen komposit dapat lebih tahan air, lebih awet, kembang susut lebih kecil, lebih tahan pelapukan/keropos dibandingkan dengan kayu, dan juga lebih ringan, lebih mudah dikerjakan dibandingkan dengan kusen beton. Kajian ini bertujuan untuk mendapatkan sifat fisik dan mekanik balok/papan semen pada komponen bangunan eternit, panel dinding, dan kusen, serta mengevaluasi pengaruh pemakaian serat limbah kayu aren dan partikel serutan bambu petung terhadap kualitas papan/balok semen komposit, sehingga didapatkan komposisi campuran serat aren dan partikel bembu yang paling baik sebagai bahan penyusun papan/balok semen komposit. 
Tabel 1. Spesifikasi benda uji untuk komposisi campuran partikel bambu:serat aren sebesar 100\%:0\%; 75\%:25\%; $50 \%: 50 \%$; dan 25\%:75\%

\begin{tabular}{|c|c|c|c|c|}
\hline \multirow{2}{*}{ No. } & \multirow{2}{*}{$\begin{array}{l}\text { Perbandingan } \\
\text { Bahan:Semen }\end{array}$} & \multirow{2}{*}{$\begin{array}{l}\text { Ukuran Partikel Bambu } \\
\text { (Lolos Ukuran Ayakan) }\end{array}$} & \multicolumn{2}{|c|}{ Jumlah Benda Uji } \\
\hline & & & Sifat Fisik & Sifat Mekanik \\
\hline 1 & \multirow{3}{*}{$1: 2$} & $1 \times 1$ & 12 & 3 \\
\hline 2 & & $0,5 \times 0,5$ & 12 & 3 \\
\hline 3 & & $0,2 \times 0,2$ & 12 & 3 \\
\hline 4 & \multirow{3}{*}{$1: 3$} & $1 \times 1$ & 12 & 3 \\
\hline 5 & & $0,5 \times 0,5$ & 12 & 3 \\
\hline 6 & & $0,2 \times 0,2$ & 12 & 3 \\
\hline 7 & \multirow{3}{*}{$1: 4$} & $1 \times 1$ & 12 & 3 \\
\hline 8 & & $0,5 \times 0,5$ & 12 & 3 \\
\hline 9 & & $0,2 \times 0,2$ & 12 & 3 \\
\hline & Jumlah & & 108 & 27 \\
\hline
\end{tabular}

Tabel 2. Spesifikasi benda uji untuk komposisi campuran partikel bambu:serat aren sebesar $0 \%: 100 \%$

\begin{tabular}{ccccc}
\hline \multirow{2}{*}{ No. } & Perbandingan & Ukuran Panjang & \multicolumn{2}{c}{ Jumlah Benda Uji } \\
\cline { 3 - 5 } & Bahan:Semen & Serat Aren $(\mathrm{cm})$ & Sifat Fisik & Sifat Mekanik \\
\hline $1: 2$ & \pm 5 & 12 & 3 \\
\hline $1: 3$ & \pm 5 & 12 & 3 \\
\hline Jumlah & $1: 3$ & \pm 5 & 12 & 3 \\
\hline
\end{tabular}

\section{METODE}

\section{Bahan dan Peralatan}

Bahan utama yang digunakan pada kajian ini meliputi serat aren, partikel bambu, semen, dan air. Serat aren merupakan limbah pengolahan pohon aren berupa serat yang didapat dari industri tepung aren yang ada di propinsi Jawa Tengah tepatnya di Desa Gemuruh, Kecamatan Bawang, Kabupaten Banjarnegara. Partikel bambu merupakan limbah yang didapat dari UGM Yogyakarta. Semen yang digunakan adalah Semen Portland semen tipe I untuk keperluan umum. Air yang digunakan adalah air sumur yang terdapat di Laboratorium Teknik Sipil Unsoed. Peralatan utama yang digunakan adalah alat pembuatan benda uji (ayakan/saringan, bak perendaman, gergaji, cetakan, semprotan, alat pres, dan alat bantu lainnya) dan alat pengujian meliputi Universal Testing Machine (UTM), timbangan, oven, dan jangka sorong.

\section{Benda Uji}

Benda uji semen komposit direncanakan dengan kerapatan sekitar $0,8 \mathrm{~kg} / \mathrm{cm} 3$. Ukuran panjang serat aren dibuat tetap, sekitar $5 \mathrm{~cm}$, dan ukuran partikel bambu dibuat 3 variasi, yaitu tertahan ayakan $1 \mathrm{~cm} \times 1 \mathrm{~cm} ; 0,5 \mathrm{~cm} \times 0,5$ $\mathrm{cm}$, dan $0,2 \mathrm{~cm} \times 0,2 \mathrm{~cm}$. Secara lengkap spesifikasi benda uji disajikan pada Tabel 1 untuk komposisi campuran pertikel bambu:serat aren sebesar 100\%:0\%; 75\%:25 \%; 50\%:50\%; dan 25\%:75\%. Untuk spesifikasi benda uji komposisi campuran pertikel bambu:serat aren $0 \%: 100 \%$ disajikan pada Tabel 2. Pengujian sifat fisika terdiri dari kadar air, berat jenis, perubahan dimensi, dan penyerapan air. Pengujian sifat mekanik meliputi kuat lentur (Modulus of Rupture) dan modulus of elastistas (MOE).

\section{Pengujian dan Analisis Data}

Spesifikasi dan prosedur pengujian sampel fisik dan mekanik balok/papan semen komposit berdasarkan ASTM D143-93. Dari hasil pengujian dilakukan pengolahan data untuk sifat fisik (kadar air, kerapatan/berat jenis, perubahan dimensi, dan penyerapan air) dan sifat mekanika meliputi tegangan lentur Modulus of Rupture dan modulus elastistas (MOE). Analisis data untuk sifat fisik diperlihatkan pada Tabel 3 dan untuk sifat mekanik disajikan pada Tabel 4.

\section{HASIL DAN PEMBAHASAN Sifat Fisik Balok/Papan Semen}

Hasil pengujian sifat fisik memperlihatkan bahwa kadar air balok/papan semen berkisar $3,22 \%-6,91 \%$. Kadar air terbesar diperoleh 
pada komposisi balok semen dengan campuran partikel bambu dan serat aren 50:50 dan ukuran partikel bambu $5 \mathrm{~cm} \times 5 \mathrm{~cm}$. Berat jenis balok/papan semen terbesar diperoleh pada campuraan partikel bambu dan serat aren 50:50 yaitu 1,3 dengan kadar semen 1:4.
Perubahan dimensi balok/papam semen diperoleh hasil terbaik dari kadar serat aren terbesar, dan mengalami penurunan seiring dengan berkurangnya kadar serat aren. Penyerapan air pada balok/papan semen

Tabel 3. Analisis sifat fisik balok/papan semen komposit

\begin{tabular}{|c|c|c|}
\hline Pengujian & Metode Uji & Rumus Analisis \\
\hline Kadar Air & $\begin{array}{l}\text { Benda uji ditimbang untuk mendapatkan } \\
\text { berat awal (BA). dalam keadaan kering } \\
\text { udara ditimbang beratnya lalu diukur rata- } \\
\text { rata panjang, lebar, dan tebalnya untuk } \\
\text { menentukan volume. Untuk selanjutnya } \\
\text { dioven dengan suhu } 103 \pm 2^{\circ} \mathrm{C} \text { selama } 24 \\
\text { jam. }\end{array}$ & $\begin{array}{l}\text { KadarAir }=\frac{B A-B K O}{B K O} \\
\text { BA }=\text { Berat awal } \\
\text { BKO = Berat kering oven }\end{array}$ \\
\hline Kerapatan & $\begin{array}{l}\text { Benda uji dalam keadaan kering udara } \\
\text { ditimbang beratnya lalu diukur rata-rata } \\
\text { panjang, lebar, dan tebalnya untuk } \\
\text { menentukan volume. }\end{array}$ & Kerapatan $=\frac{\text { Berat }}{\text { Volume }}$ \\
\hline $\begin{array}{c}\text { Pengembangan } \\
\text { Tebal }\end{array}$ & $\begin{array}{l}\text { Benda uji diukur dalam kondisi kering udara. } \\
\text { Dimensi lebar diukur pada kedua sisinya } \\
\text { kemudian dirata-rata }\left(D_{1}\right) \text {. Untuk dimansi } \\
\text { tebal diukur dari pusat benda uji. } \\
\text { Selanjutnya benda uji direndam dalam air } \\
\text { dingin selama } 2 \text { dan } 24 \text { jam, kemudian } \\
\text { diukur lagi dimensinya }\left(D_{2}\right) \text {. }\end{array}$ & $\begin{array}{l}\text { Peng. Tebal }=\frac{\mathrm{D} 1-\mathrm{D} 2}{\mathrm{D} 2} \\
\times 100 \% \\
D_{1}=\text { Dimensi awal } \\
D_{2}=\text { Dimensi akhir }\end{array}$ \\
\hline Penyerapan Air & $\begin{array}{l}\text { Pengujian penyerapan air dilakukan } \\
\text { bersamaan dengan } \\
\text { pengembangan tebal. Benda uji ditimbang } \\
\text { kemudian direndam dalam air dingin selama } \\
2 \text { jam dan } 24 \text { jam, selanjutnya ditimbang } \\
\text { kembali. }\end{array}$ & $\begin{array}{l}\text { Serap air }=\frac{B_{2}-B_{1}}{B_{2}} \times 100 \% \\
\mathrm{~B}_{1}=\begin{array}{l}\text { Berat benda uji sebelum } \\
\text { perendaman }\end{array} \\
\mathrm{B}_{2}=\begin{array}{l}\text { Berat benda uji setelah } \\
\text { perendaman }\end{array}\end{array}$ \\
\hline
\end{tabular}

Tabel 4. Analisis sifat mekanik balok/papan semen komposit

\begin{tabular}{|c|c|c|}
\hline Pengujian & Metode Uji & Rumus/Analisis \\
\hline 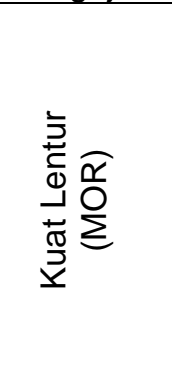 & $\begin{array}{l}\text { Pengujian lentur dilakukan dengan alat Universal } \\
\text { Testing Machine (UTM). Benda uji dengan ukuran } \\
25 \times 25 \times 41 \mathrm{~cm} \text { diletakkan pada tumpuan } \\
\text { sederhana dan diberi beban terpusat statik pada } \\
\text { tengah bentang. } \\
\text { Tाוा }\end{array}$ & $\begin{array}{l}M O R=\frac{3 P L}{2 b h^{2}} \\
\mathrm{P}=\text { Beban terpusat sampai } \\
\text { patah/runtuh } \\
\mathrm{b}=\text { lebar benda uji } \\
\mathrm{h}=\text { tebah/tinggi benda uji }\end{array}$ \\
\hline 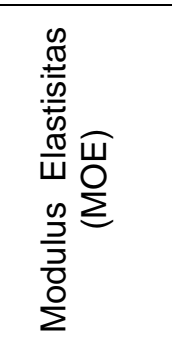 & $\begin{array}{l}\text { Pengujian modulus elastisitas sama dengan uji } \\
\text { lentur. Beban pada tengah bentang diberikan } \\
\text { secara bertahap dengan kecepatan } 6 \mathrm{~mm} / \text { menit. }\end{array}$ & $\begin{aligned} & M O E=\frac{\Delta P L^{3}}{4 \Delta y b h^{3}} \\
\Delta \mathrm{P}= & \text { Perubahan beban } \\
\Delta \mathrm{y}= & \text { Perubahan deformasi } \\
\mathrm{L}= & \text { Panjang bentang }\end{aligned}$ \\
\hline
\end{tabular}


memperlihatkan hasil terkecil pada balok semen tanpa serat aren dan terbesar pada kadar serat aren $100 \%$ atau campuran tanpa partikel bambu. Secara umum perilaku sifat fisik menunjukkan hasil terbaik pada kadar semen 1:4 dan ukuran partikel $0,2 \mathrm{~cm} \times 0,2 \mathrm{~cm}$
- 0,5 cm x 0,5 cm dengan komposisi campuran adalah 100:0 sampai dengan 50:50. Hasil pengujian dan analisis sifat fisik selengkapnya dapat dilihat pada Tabel 5.

Tabel 5. Hasil pengujian dan analisis sifat fisik balok semen/papan semen

\begin{tabular}{lcccc}
\hline \multicolumn{1}{c}{ Uraian } & Kadar Air & Berat Jenis & $\begin{array}{c}\text { Perubahan } \\
\text { Dimensi }\end{array}$ & Absorbsi \\
\hline Nilai Minimum & $3,22 \%$ & 1,11 & $32,85 \%$ & 24,785 \\
\hline Nilai Maksimum & $6,91 \%$ & 1,30 & $91,41 \%$ & 42,130 \\
\hline Perbandingan P : A hasil terendah & $0: 100$ & $100: 0$ & $100: 0$ & $100: 0$ \\
\hline Perbandingan P : A hasil tertinggi & $50: 50$ & $50: 50$ & $0: 100$ & $0: 100$ \\
\hline Uk. partikel bambu hasil terendah & $0,2 \times 0,2$ & $5 \times 5$ & $0,2 \times 0,2$ & $5 \times 5$ \\
\hline Uk. partikel bambu hasil tertinggi & $5 \times 5$ & $0,5 \times 0,5$ & $5 \times 5$ & $0,5 \times 0,5$ \\
\hline Kadar semen hasil terendah & $1: 4$ & $1: 2$ & $1: 3$ & $1: 4$ \\
\hline Kadar semen hasil tertinggi & $1: 2$ & $1: 4$ & $1: 2$ & $1: 2$ \\
\hline Keterangan: $P$ (partikel bambu) dan A (serat aren) & & & &
\end{tabular}

\section{Sifat Mekanik Balok/Papan Semen}

Hasil pengujian sifat mekanik menunjukkan bahwa tegangan lentur (MOR) balok/papan semen berkisar 4,77 Mpa - 6,59 $\mathrm{MPa}$, dengan hasil terbesar diperoleh pada komposisi balok semen campuran partikel bambu dan serat aren 50:50 dengan ukuran partikel bambu $0,2 \mathrm{~cm} \times 0,2 \mathrm{~cm}$ dan panjang serat aren sekitar $5 \mathrm{~cm}$. Kadar semen 1:3 menghasilkan tegangan lentur (MOR) terbesar yaitu 5,6 MPa. Sedangkan kadar semen 1:4 memberikan tegangan lentur (MOR) terbesar terkecil yaitu $5 \mathrm{MPa}$. Modulus elastisitas (MOE) balok semen terbesar diperoleh pada campuraan partikel bambu dan serat aren 100:0 yaitu 2398,74 MPa, pada ukuran partikel bambu $0,2 \mathrm{~cm} \times 0,2 \mathrm{~cm}$. Modulus elastisitas (MOE) tertinggi sebesar 2283,02 MPa diperoleh pada kadar semen 1:3. Hasil pengujian dan analisis sifat mekanik selengkapnya disajikan pada Tabel 6.

Tabel 6. Hasil pengujian dan analisis sifat mekanik balok semen/papan semen

\begin{tabular}{lcc}
\hline \multicolumn{1}{c}{ Uraian } & MOR & MOE \\
\hline Nilai Minimum & $4,721 \mathrm{MPa}$ & $863,687 \mathrm{MPa}$ \\
\hline Nilai Maksimum & $6,593 \mathrm{MPa}$ & $2398,743 \mathrm{MPa}$ \\
\hline Perbandingan P : A hasil terendah & $0: 100$ & $25: 75$ \\
\hline Perbandingan P : A hasil tertinggi & $50: 50$ & $100: 0$ \\
\hline Ukuran partikel hasil terendah & $5 \times 5$ & $5 \times 5$ \\
\hline Ukuran partikel hasil tertinggi & $0,2 \times 0,2$ & $0,2 \times 0,2$ \\
\hline Kadar semen hasil terendah & $1: 4$ & $1: 2$ \\
\hline Kadar semen hasil tertinggi & $1: 3$ & $1: 3$
\end{tabular}

\section{KESIMPULAN}

Berdasarkan kadar air dan berat jenis, balok/papan semen yang dihasilkan termasuk dalam standar industri menurut Bison (1975), yaitu kadar air dalam rentang $6 \%$ - 15\% dan kerapatan atau berat jenis adalah sekitar 1,25. Untuk perubahan dimensi atau pengembangan tebal, balok/papan semen masih jauh dari standar industri Bison (1975), yaitu sekitar 1,2
- $2 \%$. Berdasarkan sifat mekanik, balok/papan semen yang dihasilkan belum memenuhi standar industri menurut Bison (1975) yang mensyaratkan bahwa papan semen memiliki tegangan lentur (MOR) berkisar $9 \mathrm{MPa}-15$ $\mathrm{MPa}$ dan modulus elastisitas (MOE) berkisar $3000 \mathrm{MPa}-5000 \mathrm{MPa}$. 


\section{DAFTAR PUSTAKA}

Bison (1975). Cement - Bonded Particleboard Plant Integrated With Low Cost Housing Production Unit Case Study Prepared for FAO Portofolio of Scale Forest Industries for Developing Countries. Germany: Bison Werhe Bahre and Breten Bmtt and Co.

Handajani, M. \& Firdayanti, M., (2005). Studi Karakteristik Dasar Limbah Industri Tepung Aren. Jurnal Infrastruktur dan Lingkungan Binaan. http://www.ftsl.itb.ac.id. Diakses 12 April 2017.

Hermanto, N. I. S., et al (2005). Penyelidikan Kayu Aren Dalam Usaha Pemanfaatannya Sebagai Bahan Bangunan. (Kajian Limbah Kayu Aren di Kecamatan Dayeuhluhur, Kabupaten Cilacap). Laporan Penelitian DIPA II, Lembaga Penelitian Unsoed, Purwokerto: Unsoed.

Syafi'i, W., (1998). Pentingnya Penelitian Sifatsifat Dasar Kayu Dalam Rangka Peningkatan Efisiensi Pemanfaatan Sumber Daya Hutan. Seminar Nasional I, Masyarakat Peneliti Kayu Indonesia (MAPEKI). Bogor: Fakultas Kehutanan, IPB. 